\title{
Comparative analysis of stability of large diameter steel cylinder based on FEM and limit equilibrium
}

\author{
Chang-yi Yu' $1,2,3,4$, Ming-yue $\mathrm{Lu}^{5}$ \\ ${ }^{1}$ CCCC-Tianjin Port Engineering Institute, Ltd., 300222 Tianjin, China \\ ${ }^{2}$ CCCC First Harbor Engineering Company, Ltd., 300461 Tianjin, China \\ ${ }^{3}$ Key Laboratory of Geotechnical Engineering, Ministry of Communications, 300222 Tianjin, China \\ ${ }^{4}$ Key Laboratory of Geotechnical Engineering of Tianjin, 300222Tianjin, China \\ ${ }^{5}$ Tianjin Survey and Design Institute For Water Transport Engineering, 300000 Tianjin, China
}

\begin{abstract}
The stability mechanism of large-diameter steel cylinder under fill load has not yet formed a complete theory. In order to calculate the stability of the steel cylinder island arm structure in a certain project, the limit equilibrium and finite element method are used in this paper. The limit equilibrium method is based on the limit equilibrium of the soil inside and outside the steel cylinder, taking into account the earth pressure and friction force on the cylinder, and using moment equilibrium to calculate its stability coefficient. Secondly, the finite element strength reduction method is adopted to analyze the stability of the steel cylinder island arm structure by using strength parameters to correlate with the temperature field and changing the boundary conditions of the temperature field. The results and analysis methods of this paper provide references for the construction and design of the same type of projects.
\end{abstract}

\section{Introduction}

Foreign countries have studied the stress state and working mechanism of large diameter cylinder structure earlier. During the construction of le havre port wharf in France in 1950s, French engineers started the model experiment study of large thin-shell open caisson, analyzed the relationship between the compactness of inner packing and its load, and the contact friction value between backfill and cylinder wall, and discussed the influencing factors of the change of lateral pressure inside thin shell. Since then, France has built many wharves with different steel cylinder structures in Dunker Port and other ports, and achieved success. In the mid-1960s, the Inland River Survey and Design Institute of the former Soviet Union studied the interaction between the large-diameter gravity thin shell and foundation soil and inner filler, and put forward the conclusion that the friction between the thin shell and soil has great influence on the stability of the whole structure. In addition, wharves with steel cylinder structure were also built in Riga daud Lake and Klaipeter in the former Soviet Union. Up to now, steel cylinder wharf has been widely used in port engineering in France, former Soviet Union, Canada, Japan and other countries.

Since 1980s, our country has carried out experimental research on steel cylinder structure, and completed such projects as Shijiu Port Coal Wharf, Tianjin Port Breakwater and Bank Protection
Experimental Project, Zhuhai Jiuzhou Island Port, Fangchenggang Berth No.8 and Guangdong Panyu Nansha Joint Wharf[1].

The stability of steel cylinder itself is mainly simulated by limit equilibrium theory and finite element method. The limit equilibrium calculation of steel cylinder stability can simplify the stress mode of steel cylinder as anchor-free sheet pile, and consider the horizontal shear force of soil acting on the bottom of cylinder, the reaction force of soil at the bottom of cylinder, and the effect of vertical friction of soil inside and outside the cylinder on the stability of cylinder wall. The earth pressure intensity in the cylinder is approximately distributed according to Janssen curve; the earth pressure intensity in front of the cylinder is approximately trapezoidal distribution, which is calculated according to Rankine passive earth pressure; the earth pressure intensity behind the cylinder is approximately distributed in triangle, and the clay earth pressure is calculated according to Rankine earth pressure [2]. In the limit state, the cylinder is mainly capsized and unstable. During the overturning process of steel cylinder, the earth pressure below the rotation point behind the cylinder and above the rotation point in front of the cylinder gradually increases. The anti-roll moment formed by the earth pressure is the main part of the total anti-roll moment [3]. When using the limit equilibrium method to analyze, another key problem is the determination of the rotation center of the cylinder, 
which has been calculated by the corresponding theory [4]. With its strong adaptability, the finite element method can calculate the stability of steel cylinder under various working conditions, such as consolidation [5] and creep [6], and overcome the difficulties of theoretical calculation of earth pressure and rotation center [7], and can be used for 3D model calculation to avoid the errors caused by $2 \mathrm{D}$ limit equilibrium theoretical calculation.

In this paper, based on the previous achievements, finite element method and limit equilibrium method are used to analyze a project, which can provide reference for the safe and reliable construction of the same type of project.

\section{Engineering brief introduction}

A project is located in Lingdingyang, with complex geological conditions. The upper part of the overburden is mainly composed of marine muddy soil mixed with sand, while the lower part is alluvial sand and local round gravel soil. The thickness of the overburden varies from $15.5 \mathrm{~m}$ to $57.8 \mathrm{~m}$, and the bedrock is Yanshanian granodiorite and granite.

In the calculation, it is assumed that the steel cylinder is a steel body, and the soil layer parameters are shown in Table 1.

Table 1 Soil Layer Parameters

\begin{tabular}{|c|c|c|c|c|c|c|}
\hline Soil & $\begin{array}{c}\text { thickness } \\
(\mathrm{m})\end{array}$ & $\begin{array}{c}\text { wet density } \\
(\mathrm{g} / \mathrm{cm} 3)\end{array}$ & $\begin{array}{c}\text { compression modulus } \\
(\mathrm{MPa})\end{array}$ & $\begin{array}{c}\text { Poisson's } \\
\text { ratio }\end{array}$ & $\begin{array}{c}\text { friction } \\
\text { angle }\left({ }^{\circ}\right)\end{array}$ & $\begin{array}{c}\text { cohesion } \\
(\mathrm{kPa})\end{array}$ \\
\hline Mud(2)1 & 9 & 1.59 & 1.83 & 0.3 & 10.0 & 4.3 \\
\hline Silt(2)2-4 & 2 & 2.017 & 5.09 & 0.3 & 28 & 7.6 \\
\hline Mud(2)2 & 6 & 1.57 & 1.776 & 0.3 & 6.3 & 5.0 \\
\hline Mud(2)3 & 2.2 & 1.754 & 2.75 & 0.3 & 18.0 & 14.4 \\
\hline Silty clay(3)2 & 1.1 & 2.02 & 6.33 & 0.3 & 30 & 0 \\
\hline Coarse sand(3)7 & 1.6 & 2.04 & 19 & 0.3 & 30 & 14 \\
\hline $\begin{array}{c}\text { Medium weathered } \\
\text { rock66w2 }\end{array}$ & 10.3 & 1.82 & 60 & 0.3 & 30 & 24 \\
\hline $\begin{array}{c}\text { Slightly weathered } \\
\text { rock66w1 }\end{array}$ & 12.5 & 1.80 & 80 & 0.3 & 27 & 28 \\
\hline Backfill sand & --- & 1.9 & 15 & 0.3 & 28 & 1 \\
\hline Dixin stone & --- & 1.7 & 25 & 0.3 & 25 & 5 \\
\hline Compacted sand pile & --- & 1.7 & & & 25 \\
\hline
\end{tabular}

\section{3 limit equilibrium method}

According to the regulations of the code, the stability of the cylinder structure should be checked according to the limit state of bearing capacity, and the anti-inclination stability should meet the following expression:

$$
\gamma_{0}\left(\gamma_{E} M_{E}+\gamma_{P} M_{P}\right) \leq \frac{1}{\gamma_{d}}\left(\sum \gamma_{i} M_{i}\right)
$$

Where: $\gamma_{0}$-structural importance coefficient;

$\gamma_{\mathrm{d}}-$ structural coefficient;

$\gamma_{\mathrm{E}} \longrightarrow$ partial coefficient of earth pressure;

$\mathrm{M}_{\mathrm{E}} \longrightarrow$ overturning moment of permanent total earth pressure;

$\mathrm{M}_{\mathrm{P}}$ - overturning moment of wave pressure standard value under wave crest action;

$\gamma_{\mathrm{P}} \longrightarrow$ partial coefficient of wave horizontal force;

$\gamma_{i}-$ partial coefficients of various stabilization effects;

$\mathrm{M}_{\mathrm{i}}$ - each anti-roll moment.

Now define a coefficient $\mathrm{k}$ (which can be called stability coefficient):

$$
k=\frac{\frac{1}{\gamma_{\mathrm{d}}}\left(\sum \gamma_{\mathrm{i}} M_{\mathrm{i}}\right)}{\gamma_{0}\left(\gamma_{\mathrm{E}} M_{\mathrm{E}}+\gamma_{\mathrm{P}} M_{\mathrm{P}}\right)}
$$

Obviously, satisfying formula (2) is equivalent to $\mathrm{k} \geq$ 1. That is, the structure is stable when the stability coefficient of the large cylinder satisfies $k \geq 1$.

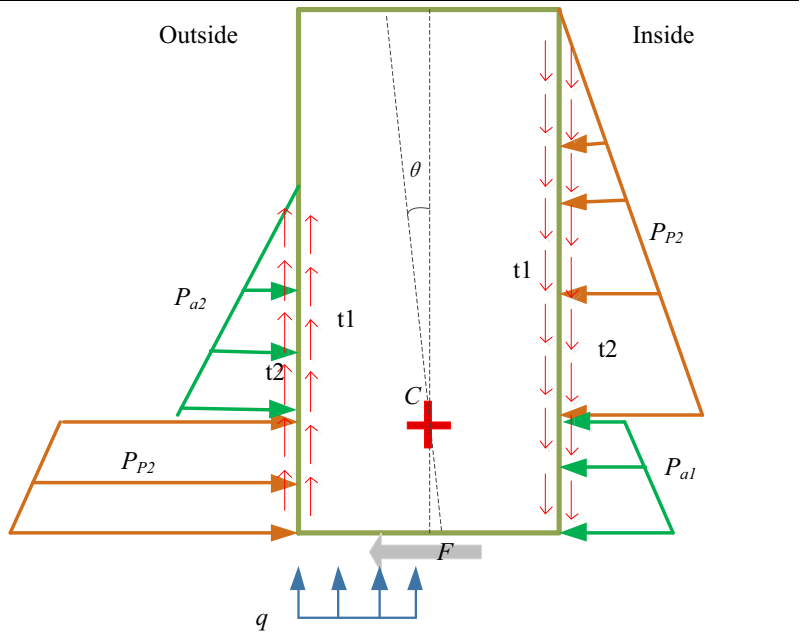

Fig. 1 Stress Diagram of Steel Cylinder in Limit State

For example, a large cylinder with deep clay bearing water retaining function, besides the earth pressure inside and outside the cylinder, because the structure has a large side surface, the friction of the inner and outer soil also plays an important role in the stability of the structure. In addition, when the large cylinder capsizes, the foundation will produce vertical reaction force and horizontal tangential force at the bottom of the cylinder. It is assumed that under the action of wave force, the structure tends to rotate around point $\mathrm{C}$ on the axis, and its stress in critical state is shown in Figure 1.

In fig. 1, active earth pressure $\mathrm{Pa} 2$ and active earth pressure Pal produce overturning moment, which is unfavorable to the stability of the structure. Passive earth 
pressure Pp2, passive earth pressure $\mathrm{Pp} 1$, lateral friction of inner and outer walls t1, t2, horizontal tangential force $\mathrm{f}$ of foundation, reaction force $\mathrm{q}$ of foundation and pressure $\mathrm{s}$ of stuffing in the cylinder will produce anti-tilting moment.

According to the formula deduced by Liu Jianqi, the rotation angle $\theta$ and the distance y0 from the rotation point $\mathrm{C}$ to the mud surface can be determined:

$$
\begin{gathered}
\theta=\frac{3\left[8 \mathrm{EH}_{0} \mathrm{~h}+12 \mathrm{M}_{0}+(8 \mathrm{e}-6) \mathrm{q}_{\mathrm{x}} \mathrm{Dh}^{2}\right]}{18 \mathrm{k}_{0} \mathrm{DW}+(9-8 \mathrm{E}) \mathrm{nDh}^{4}+(36-24 \mathrm{E}) \mathrm{K}_{\mathrm{T}} \mathrm{h}^{2} \mathrm{~A}} \\
\mathrm{y}_{0}=\frac{6\left(\mathrm{H}_{0}+\mathrm{q}_{\mathrm{x}} \mathrm{Dh}\right)+2\left(3 \mathrm{~K}_{\mathrm{T}} \mathrm{hA}+\mathrm{nDh}^{3}\right) \theta}{3\left(2 \mathrm{~K}_{\mathrm{T}} \mathrm{A}+\mathrm{nDh}^{2}\right) \theta}
\end{gathered}
$$

$D$ - outer diameter of cylinder

$h$ - the sinking depth of the cylinder;

$n$-Proportional coefficient of horizontal foundation coefficient varying with depth;

$A$-basal area;

$W$-bending section coefficient of rigid base of cylinder, $\mathrm{W}=\pi\left(\mathrm{D}^{3}-\mathrm{D}_{0}^{3}\right) / 32$

$D_{0}$ - equivalent inner diameter of cylinder,D0 $=30.9 \mathrm{~d}$, $\mathrm{d}$ is inner diameter;

$K_{T}$ - shear deformation coefficient of foundation, $K_{T}=(0.4-0.6) K_{0}, K_{0}=n \cdot h$;

$\mathrm{H} 0 、 \mathrm{M} 0$ - horizontal load and bending moment acting on the sinking surface respectively;

$q_{x}$ - uniformly distributed load generated by soil and remaining water above the sinking surface

$E$ - parameter, $E=1+K_{T} A /\left(n D h^{2}+2 K_{T} A\right)$

The values of action partial coefficients and the calculation results of anti-roll moment are here: Anti-tilting moment is $135330.1 \mathrm{kN} \cdot \mathrm{m}$. Anti-tilting moment is $69973.41 \mathrm{kN} \cdot \mathrm{m}$. After sand filling in the island, the soil of the whole model is reduced synchronously, and the most unstable points in different stages are automatically found.

According to the displacement catastrophe theory of finite element strength reduction method, the reduction factor corresponding to the displacement catastrophe point is the safety factor. It can be seen from the curve in Figure 3.

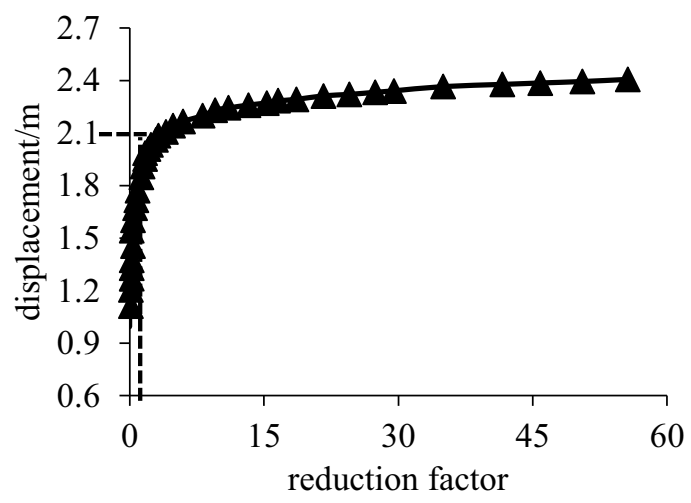

Fig. 2 Variation curve of reduction factor

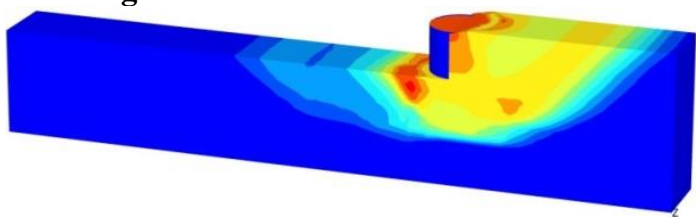

Fig. 3 Overall sliding surface view
The safety factor calculated by the limit equilibrium method is 1.91, while the safety factor calculated by the finite element method is 2.1 . They are close to each other, but there are some differences, which may be due to the following reasons: when calculating the safety factor by limit equilibrium method, the steel cylinder is simplified into a two-dimensional model, while the finite element method calculates a three-dimensional model; In the limit equilibrium method, the soil pressure is divided into active earth pressure and passive earth pressure, whose size and area are different from the finite element results. In the finite element calculation, the areas and distribution laws of active earth pressure and passive earth pressure are complex.

\section{Conclusion}

In this paper, the stability of an engineering steel cylinder structure is compared and analyzed by using limit equilibrium and finite element method. The safety factor of steel cylinder obtained by limit equilibrium analysis is 1.93, while the safety factor obtained by finite element method is slightly larger and the result is 2.1. The differences between the two models come from the following aspects: the limit equilibrium method simplifies the steel cylinder into a two-dimensional model, while the finite element model is a three-dimensional model, and its stress state is different. It is suggested that the limit equilibrium method should be used in the stability analysis of steel cylinder in the same type of engineering to ensure the safety and reliability of the project.

\section{References}

1. JUN D, TINGYIN Z. Seismic Response Analysis for Large Diameter Steel cylinder Towers Built on Building [J]. Special Structures, (2000), 10(13): 3241-3251.

2. WEI-YI L I, YONG-CHANG L U. Design and Application Prospect of Large-diameter Steel Cylinder Quay Structure [J]. Port \& Waterway Engineering, (2004), 15(23): 142-150.

3. YUAN M, WENHUA X U, YONGQUAN L I, et al Study and application of vibratory sinking equipment and technology for steel cylinder with large diameter [J]. Construction Machinery, (2004), 8(4): 231-237.

4. DONG Y. Stability Analysis of a Landslide Based on Methods of Limit Equilibrium and Finite Element Strength Reduction [J]. Journal of China Three Gorges University, (2012), 1(2): 21-31.

5. MENG F L, KONG L L, LIU H B, et al. Development and application of vibration sinking technology and equipment of large diameter steel cylinder $[\mathrm{J}]$. China Harbour Engineering,(2015), 8(29): 128-135.

6. ZHOU H X, DONG Z L, CHEN P S. Deformation characteristics of large-diameter steel cylinders $[\mathrm{J}]$. 
Port \& Waterway Engineering, (2015), 21(11): 324-329.

7. CHI D U, HAN D, ZENGHUI L I, et al. Numerical simulation research of power spinning process for
D406A steel large diameter cylinder [J]. China Metalforming Equipment \& Manufacturing Technology, (2016), 29(11): 31-41 